\title{
Las relaciones México-Estados Unidos, 1756-2010
}

\author{
Leonardo Curzio*
}

A finales de 2012, apareció una impresionante obra sobre las relaciones México-Estados Unidos, que abordaba desde 1756 hasta 2010, producto del titánico esfuerzo de cuatro historiadores: Marcela Terrazas, Gerardo Gurza, Paolo Riguzzi y Patricia de los Ríos. Su importancia radica en los méritos (no escasos) a los que me referiré cumplidamente en las siguientes líneas, pero también al contexto en el que aparece. Dice el lugar común de las contraportadas de muchos libros que la obra en cuestión "viene a cubrir un vacío" en la historiografía. En este caso, la trillada expresión es válida porque la investigación a cuatro manos de los autores aludidos supone una vigorizadora contribución.

Hace aproximadamente cuatro décadas, Josefina Zoraida Vázquez y Lorenzo Meyer constataban que, a pesar de la importancia intrínseca de las relaciones entre México y Estados Unidos, no teníamos en la bibliografía especializada muchas obras generales que revisaran sistemáticamente la compleja vecindad de estos dos grandes países que comparten el territorio septentrional de América. En la bibliografía disponible en Estados Unidos se citaban las obras de Rippy, Callahan, Howard F. Cline y algunas más de otros autores estadunidenses. Por el lado mexicano, se evocaba a Alberto María Carreño, Gastón García Cantú y Luis G. Zorrilla. La obra sintetizadora de Vázquez y Meyer (2003) marcó una época y, en muchos sentidos, sigue siendo una influyente línea de interpretación para entender la relación bilateral.

Ante este panorama, es comprensible que se reciba con entusiasmo un nuevo intento de sistematizar las relaciones bilaterales. El esfuerzo

\footnotetext{
* Investigador del CISAN, UNAM, e investigador invitado en el CIDE. La lectura de esta obra y la elaboración de la reseña se realizaron, entre otras actividades, durante el periodo sabático del que disfrutó en el ciDE; leonardocurzio@hrm.com.mx
} 
El esfuerzo de los autores de esta colosal empresa es dar coherencia a más de dos siglos de relaciones bilaterales, historia marcada por guerras, despojos, desconfianza e incomprensión, pero también por un indisoluble entrelazamiento entre las dos naciones.

de los autores de esta colosal empresa es dar coherencia a más de dos siglos de relaciones bilaterales, historia marcada por guerras, despojos, desconfianza e incomprensión, pero también por un indisoluble entrelazamiento entre las dos naciones. No hay país que haya influido tanto en configurar el rostro de México como su vecino norteño, y probablemente ningún país (en singular) haya influido tanto en moldear a Estados Unidos como lo ha hecho México. La relación, por supuesto, ha variado a lo largo de los años y no hay forma de ver cada capítulo fuera del contexto económico, político e intelectual de cada nueva coyuntura del sistema internacional. Hay, sin embargo, algunas regularidades que con el correr de los años han tenido un poderoso influjo para configurar la imagen que los mexicanos tienen de los vecinos y viceversa. Es asombroso constatar la enorme vitalidad de los prejuicios y su habilidad para viajar por los siglos con nuevo ropaje, pero con la misma esencia.

En suma, este trabajo enriquece el panorama bibliográfico, además de arrojar luz sobre aspectos poco conocidos de la relación que, por razones patrióticas (u otras menos santas), se pasan bajo un prudente silencio en las interpretaciones tradicionales de la relación bilateral (las negociaciones de apoyo por cesión territorial, por ejemplo) para favorecer el dictum, mil veces citado, del "Pobre México, tan lejos de Dios [...]". La obra en cuestión (especialmente el primer volumen, que va de 1776 a 1867, y en las dos primeras partes del segundo volumen, es decir, hasta 1950) provee nuevos ángulos de lectura para procesar, renovadamente, algunos aspectos de la poliédrica relación entre estos dos países.

La obra está dividida en dos volúmenes, ambos de considerable extensión. Cuenta con un muy completo aparato crítico que nos permite constatar, de entrada, que pese al escaso número de obras generales que traten la relación bilateral ${ }^{1}$ contamos con una impresionante cantidad de monografías, estudios regionales y sectoriales sobre diferentes etapas y momentos relevantes de la relación bilateral. De hecho, ésa es una de las más valiosas contribuciones para la comunidad especializada (tanto en la docencia como en la investigación) que esta obra colectiva nos ofrece. La revisión historiográfica denota el profundo conocimiento del tema y la madurez intelectual de los autores. La bibliografía citada nos ofrece un abanico deslumbrante de obras en los ámbitos político, económico, cul-

\footnotetext{
${ }^{1}$ Terrazas había realizado ya un trabajo de sistematización de la bibliografía disponible para el estado de las relaciones entre México y Estados Unidos en formato digital (2005).
} 
tural (incluso turístico). Cuenta, además, con valiosos anexos que ofrecen una relación a los gobernantes de los dos países, los enviados, plenipotenciarios y más adelante a los embajadores, así como de los tratados bilaterales que a lo largo de más de dos siglos se han firmado entre ambos países.

Me parece importante que, además de los institutos y centros de la UNAM que la editaron, la Secretaría de Relaciones Exteriores haya incluido su sello. Juzgo imprescindible que todo diplomático mexicano dedique tiempo a leer el texto y así tener conciencia de la cantidad de fuentes que se pueden consultar.

La obra se maduró a lo largo de años de trabajo, que no solamente se utilizaron en revisión de archivos, manuscritos y documentos, sino en un intenso diálogo con académicos de distintas universidades. El trabajo se complementa con un muy útil aparato cartográfico y fotográfico que confiere a la obra prestancia y agilidad.

La presentación corre a cargo del prestigiado historiador británico Alan Knight, quien, en una perspicaz lectura, demuestra que uno de los grandes méritos de la obra que comentamos es que los países en sus interacciones no se comportan como actores unitarios, sino como colectivos complejos que obedecen a dinámicas particulares que se conectan de forma variada (Terrazas, 2012: 15).

Queda claro, igualmente, que la versión victimista de una cierta historiografía mexicana debe complementarse con una visión mucho más intensa y matizada de la interacción entre estos dos países, los dos pueblos y las dos economías. Una visión renovada que incorpore nuevos elementos explicativos, como la endémica debilidad del Estado mexicano y su incapacidad para custodiar sus fronteras, poblar su territorio norteño, edificar infraestructura y vías de comunicación; articular un proyecto de modernización propio que garantice, al mismo tiempo, su modernización y preservar su especificidad e independencia.

Muchos historiadores, como Paul Johnson (2004), por ejemplo, se han preguntado si el afán expansivo de Estados Unidos se habría moderado de haber encontrado en el sur a un vecino bien organizado y coherente, capaz de poblar, gobernar y defender su territorio. La pregunta es retórica, pero no carece de interés analítico. Y viceversa, si México habría podido madurar su proyecto nacional de otra manera de no haber tenido, desde los albores de su vida independiente, una presión continua sobre su integridad territorial por parte de un vecino agresivo y decidido a
Juzgo imprescindible que todo diplomático mexicano dedique tiempo a leer el texto y así tener conciencia de la cantidad de fuentes que se pueden consultar. La obra se maduró a lo largo de años de trabajo, que no solamente se utilizaron en revisión de archivos [...] sino en un intenso diálogo. 
Estados Unidos se desarrolló en gran medida como

lo hizo por su insaciable apetito expansivo, y México, a pesar de todo, logró preservarse como Estado independiente. Las relaciones entre ambos países han quedado marcadas por esa diferencia. cumplir lo que algunos años más adelante se denominaría "el destino manifiesto".

Pero como el hubiera no existe, Estados Unidos se desarrolló en gran medida como lo hizo por su insaciable apetito expansivo, y México, a pesar de todo, logró preservarse como Estado independiente. Las relaciones entre ambos países han quedado marcadas por esa diferencia. La pregunta que salta al concluir la lectura del libro es si esto debe ser así para siempre o en una nueva coyuntura se escribirá un nuevo capítulo. Las condiciones son radicalmente diferentes en el siglo XXI: el 10 por ciento de la población de Estados Unidos es de nuestra estirpe y ambas economías intercambian más de mil millones de dólares diarios. Pero dejemos las preguntas derivadas del estudio y regresemos al texto.

La obra toma una distancia temporal adecuada para ayudarnos a entender que la dinámica demográfica y geopolítica de América del Norte no empezó con la independencia de los dos países. Hay una historia previa que es muy útil conocer: la expansión de la frontera de las colonias originales (protagonizada por los colonos americanos) se produce con una compleja red de alianzas entre franceses, ingleses y diversos cacicazgos indios. Una buena parte de la dinámica territorial y poblacional estadunidense, previa a la independencia, se explica por el movimiento de los imperios y la correlación de fuerzas, tanto en Europa como en el Caribe. Hacia finales del siglo XVIII, dos grandes actores están a punto de desaparecer del mapa político americano (España y Francia) y dos nuevos países aparecerán como actores relevantes (el gobierno de Estados Unidos y, algunos años después, México); sin embargo, en los estertores del imperio español, hubo una sucesión importante de cambios territoriales y fronterizos en la parte sureste de lo que hoy es Estados Unidos y que afectarán al naciente México en su porción septentrional. Los reacomodos de población y fronteras en Florida, Luisiana y la cuenca del Mississippi son particularmente acelerados en la etapa previa a que México emerja como nación independiente. La obra en cuestión nos permite transitar por ese complicado sistema de alianzas y tratados, y se presenta como un detallado atlas para recorrer los meandros de los vaivenes políticos de las potencias europeas y la vocación expansionista de la joven república americana.

Por consiguiente, no es casual - tampoco un hecho inesperado ni sorpresivo-, como lo sugirió cierta tradición historiográfica oficialista, el caso de Texas. Los autores demuestran que la Nueva España había 
sido incapaz de poblar y asentar un gobierno en América del Norte y su política de colonización había sido residual (y en muchos sentidos un fracaso). Este estado de cosas es heredado por el México independiente. De hecho, es una cruel paradoja que mientras millones de ciudadanos de Europa, Asia (incluso de México) hayan llegado en flujos millonarios a poblar Estados Unidos, ni la colonia ni México concitaron la atención de un flujo estable de emigrantes (nacionales o extranjeros) para asentarse en su porción septentrional, salvo los colonos estadunidense que no lograron ocultar su vocación secesionista, con la independencia de Texas como primera consecuencia.

Es una ironía de la historia que los llamados gubernamentales a poblar California y Texas en los primeros años de la vida independiente de México no hayan tenido eco y un siglo después (ya bajo el dominio estadunidense) los estados del sur se hayan convertido en un poderosísimo imán para los mexicanos. Entre 1820 y 1860, por ejemplo, llegan a Estados Unidos cinco millones de personas y, en contraste, México recibió entre 1827 y 1829 tan sólo 704 . El entusiasmo criollo por atraer pobladores extranjeros no cuajaba, mientras más y más colonos estadunidenses ocupaban los territorios texanos y posteriormente otras entidades.

La pérdida territorial de lo que hoy es la parte sur de Estados Unidos podría calificarse de lo que sea, menos de sorpresiva. Es producto de un proceso ideológico, económico, demográfico y, en definitiva, militar que se fue gestando, por lo menos, con un siglo de anticipación.

Es verdad que el nudo de intereses locales y los problemas entre los gobiernos estatales y federal impidieron a México dar una respuesta coherente al desafío de Texas, pero debemos incorporar al análisis el problema congénito de los sucesivos gobernantes de México, que es su escaso conocimiento de los procesos externos. Nuestro (es decir, de México) desinterés por entender lo que ocurre allende nuestra fronteras es la fuente de nuestra secular incapacidad de anticipar. Desde Moctezuma, quien jamás comprendió el juego del conquistador hasta que lo apresaron (a pesar de que las naves ibéricas tocaron costas americanas tres décadas antes de llegar a México-Tenochtitlan), hasta muy avanzado el siglo xx, es frecuente detectar en cada una de las etapas que los autores estudian con detenimiento, que la falta de estudio sistemático de lo que ocurre en el exterior ha llevado a México a ser más pasivo y resistente que activo y propositivo.

La pérdida del territorio nacional marcará las décadas venideras y, a lo largo de los siglos, el temor mexicano a perder su territorio por el avance
La pérdida territorial de lo que hoy es la parte sur de Estados Unidos podría calificarse de lo que sea, menos de sorpresiva.

Es producto de un proceso ideológico, económico, demográfico $y$, en definitiva, militar que se fue gestando, por lo menos, con un siglo de anticipación. 
Estados Unidos experimentó, desde

la década de los veinte, una enorme

presión de

pioneros,

comerciantes y

especuladores para

avanzar hacia el

sur: Kentucky,

Alabama y

Tennessee.

de colonos y después de filibusteros, tema que, por cierto, merece un amplio tratamiento por parte de los autores. El caso texano (y todas sus implicaciones) es brillantemente explicado -y en mi opinión merecería ser revisado con detalle por todos los formuladores de política exterior.

Después viene una muy documentada y compleja narración del periodo previo a la guerra. Estados Unidos experimentó, desde la década de los veinte, una enorme presión de pioneros, comerciantes y especuladores para avanzar hacia el sur: Kentucky, Alabama y Tennessee. El impulso expansionista se daba ideológicamente sustentado en una estructura bifronte: por un lado, la idea del progreso estadunidense, basado en la libertad y el racionalismo, frente a un pueblo (como el mexicano) que venía de dos tradiciones que el estereotipo anglosajón había etiquetado como "degeneradoras": la indígena y el catolicismo español. Desde finales del siglo xvII, se tienen noticias de "misiones" para "regenerar" a México y reorientarlo hacia un modelo protestante y más acorde con los valores imperantes en Nueva Inglaterra (que hasta Huntington se asumen como los articuladores de la nacionalidad), pero el esfuerzo había sido marginal.

En el siglo xIX es cuando esta jauría de prejuicios (y desembozado desprecio) empiezan a vertebrarse con una política exterior abiertamente expansionista. La segunda es la expansión de los estados esclavistas. No es casual que, poco después de concluida la anexión de territorios mexicanos, estallara la guerra civil en Estados Unidos. México, en ese periodo, es presa de todos sus demonios: caciquismos, intrigas regionales y una incapacidad de gestionar su territorio.

En el informe redactado por Lorenzo de Zavala, se empiezan a delinear las imágenes emergentes del estadunidense y del mexicano que darán lugar a múltiples prejuicios ${ }^{2}$ que en muchos sentidos siguen vigentes. La imagen de México es sesgadamente mala desde sus primeros años, en gran medida alimentada por los citados prejuicios antiespañoles de los angloestadunidenses, formados en siglos anteriores y por el desprecio de los pueblos amerindios. Pero también por una corriente literaria que retrata ya al México independiente de forma poco favorable. El mul-

\footnotetext{
2 "El norteamericano es un pueblo laborioso, activo, reflexivo, circunspecto [...] orgulloso y perseverante [...]. El mexicano es ligero, perezoso, generoso y casi pródigo, vano, guerrero, supersticioso, ignorante y enemigo de todo yugo. El norteamericano trabaja, el mexicano se divierte. En [...] Estados Unidos todos son propietarios y tienden a aumentar su fortuna, en México los pocos que hay, la descuidan y algunos la dilapidan (Terrazas y Gurza, 2005: 163).
} 
ticitado informe de Poinsett, por tomar un caso, describe la Ciudad de México (y su orgulloso centro) como un lugar inundado, pestilente y lleno de ladrones. No fue un buen arranque en términos de imagen. Otros viajeros resaltarán muy críticamente algunos rasgos de nuestro carácter y de la enorme corrupción que imperaba en la vida pública. Esta asimetría en las percepciones mutuas reforzaba los componentes mesiánicos, excepcionalitas y expansivos del americanismo modernizador. En muchos sentidos, su guerra de colonización territorial y despojo se presentaba, ante la opinión estadunidense y mundial, como una cruzada modernizadora para sacar a México de las tinieblas coloniales españolas y la oscuridad del mundo indígena.

La contribución de los autores al estudio de la imagen de México en Estados Unidos a lo largo de la historia es excepcional. En cada etapa, nos proponen una síntesis de la obra de viajeros estadunidenses a México y de mexicanos a Estados Unidos. Tal vez no sea demasiado pedir que para la segunda edición incorporen un cuadro completo de estas obras (como el que aparece en el vol. 2, 183).

La guerra México-Estados Unidos es explicada con los suficientes matices como para jubilar, de una vez por todas, la idea ampliamente difundida de dos fuerzas perfectamente diferenciadas en pugna por la soberanía territorial de California, Nuevo México y Arizona. Por un lado, un bloque unitario de beligerantes expansionistas estadunidenses y, por el otro, un frente de patriotas mexicanos luchando abnegadamente por defender su territorio.

La guerra 1846-1848 demuestra, en realidad, que México vivía cuatro guerras diferentes. La primera (y más obvia) era la expansión estadunidense, en detrimento de su territorio y la ocupación de su capital. La segunda era la querella ideológica que impedía al país presentar un frente unitario ante el invasor. En plena guerra, algunas fracciones federalistas consideraban benéfico el ingreso de las tropas invasoras, por así convenir a sus proyectos finales. La tercera guerra era la de los integrantes de la federación. Muchos gobiernos estatales se negaron a colaborar con los esfuerzos nacionales y algunos de ellos se declararon neutrales, como si la guerra no fuese contra ellos. La cuarta era la guerra social. Mientras la elite criolla soñaba con dar coherencia territorial y política al patriotismo criollo, la inmensa mayoría de la población, de estirpe indígena, no tenía vínculo alguno con esa entelequia llamada México. Para ellos, la opresión por parte de las elites criollas y extranjeras, así como la presión creciente

La contribución de los autores al estudio de la imagen de México en Estados Unidos a lo largo de la historia es excepcional. En cada etapa nos proponen una síntesis de la obra de viajeros estadunidenses a México y de mexicanos a Estados Unidos. 
Otra de las valiosas aportaciones de esta obra es poner

de relieve la importancia de la

Doctrina Monroe en la política exterior estadunidense y la ubicación contextual de lo que llamaríamos

"la anomalía mexicana". sobre los territorios en los que se asentaban, era su principal problema. No es extraño, en consecuencia, que los "polkos" se negaran a contribuir más al esfuerzo de la guerra y muchas comunidades indígenas, simple y llanamente, no se sintieran interpeladas por lo que estaba ocurriendo.

Es interesante constatar que cuando el ejército estadunidense invadió México emulaba la conquista española del siglo XVI, como si quisieran reescribir la historia. Los formuladores de política exterior y militar hacia México estaban muy influidos por la entonces popular historia de la conquista de México escrita por William H. Prescott (2004). En resumen, quisieron presentar su guerra anexionista como una reedición de la epopeya cortesiana y dar algún lustre a lo que había sido un despojo en toda la línea, con pocos tintes de heroísmo.

Otra de las valiosas aportaciones de esta obra es poner de relieve la importancia de la Doctrina Monroe en la política exterior estadunidense y la ubicación contextual de lo que llamaríamos "la anomalía mexicana". Como es sabido, en 1823 el presidente Monroe acuñó el principio doctrinario de que el continente no estaría sujeto a nuevos intentos colonialistas de potencias extracontinentales. Para infortunio de México, el principio no pudo convertirse en apoyo efectivo y solidario cuando el ejército francés se desplegó en territorio nacional. La enorme difusión que en Estados Unidos se le da al 5 de mayo refleja la anomalía histórica que supone una abierta intervención europea en su vecino del Sur. Es claro que la guerra civil que ensangrentaba por aquellos años a Estados Unidos es la razón por la cual Francia se movió a sus anchas, convirtiendo en letra muerta la citada doctrina.

Son particularmente atractivos los capítulos que tratan este periodo de la guerra civil, porque, más allá de la descripción general, nos permite conocer interacciones fronterizas de altísima complejidad (y ambigüedad) para abrir espacios de comercio con los estados del Sur y, al mismo tiempo, tratar de obtener el apoyo del gobierno de Lincoln.

Otro de los aspectos relevantes de la obra es la posibilidad de ubicar las relaciones comerciales entre ambos países en una línea temporal amplia. Desde las vicisitudes del primer tratado comercial 1825-1826, hasta el TLCAN, hay una ingente cantidad de información sobre la interacción económica entre los dos países, sus altas y bajas, la cercanía y la distancia, pero, en términos más amplios, la incomodidad política e ideológica que ha generado en México la integración económica y comercial con sus vecinos. En más de dos siglos, no se han sentado las bases de un modelo de 
comercio e intercambio económico que fomente la idea de pertenencia a un espacio económico mutuamente benéfico, que construya confianza y que no sea visto como un negocio rapaz para beneficio de un grupo selecto. En otras palabras, con todas las variantes que uno encontraría en dos centurias de relación, no hemos logrado sentirnos cómodos con la interdependencia. Ellos tampoco, pero la asimetría los ha beneficiado siempre.

En el segundo volumen se estudia la relación bilateral a partir de 1866, cuando en México empezaba a asentarse ya el funcionamiento de algo parecido a un Estado y Estados Unidos empezaba a actuar como potencia imperial.

Mientras México buscaba un camino propio para su modernización, equilibrando el enorme poder de las corporaciones estadunidenses, los vecinos iniciaban el despliegue de su poder naval y su expansión territorial. La doctrina Monroe se complementa con el llamado corolario Roosevelt, con el que se arroga responsabilidades de policía mundial. Los desencuentros dejarán de darse en la esfera territorial para pasar al terreno económico y político. El proyecto diversificador de Díaz fracasó y nos encaminó a un siglo xx en el que la relación de México con el mundo es fundamentalmente a través de sus vecinos y en función de sus prioridades y problemáticas.

En el libro queda muy claro cómo Gran Bretaña fue remplazada por Estados Unidos (como principal socio comercial) en el último tramo del siglo XIX y marcó una creciente interacción entre grupos económicos estadunidenses y sus socios mexicanos. "Hacia 1885, ya operaban en el norte de México intereses considerables, por sus dimensiones económicas [...] para 1885 operan por lo menos 80 compañías estadunidenses en México. Dentro de este conjunto, 90 por ciento lo constituyen compañías mineras y ferrocarrileras" (Riguzzi y de los Ríos, eds., 2012: 86-87). Algunos años después, vendrá la iniciativa de las empresas ligadas al petróleo que posteriormente se convertirán en una fuente creciente de conflictos por su facciosa participación en la formulación de la política exterior estadunidense a México.

Aunque, de 1866 en adelante, muchas cosas cambiaban, no todo era nuevo en la relación bilateral. Algunos temas ligados a la frontera tienen una perturbadora vitalidad y casi siempre por malas razones. Desde 1826, ambos países polemizaron por la responsabilidad de cuidar la frontera común. Poinsett consiguió incluir un principio de compromiso para que ambos se comprometieran a evitar las invasiones de los "indios hostiles"
En el segundo volumen se estudia la relación bilateral a partir de 1866, cuando en México empezaba a asentarse ya el funcionamiento de algo parecido a un Estado y Estados Unidos empezaba a actuar como potencia imperial. 
La frontera o "belicosos". El tema de quién era el responsable de custodiar la fronte-

es una fuente de

conflictos, pero

también es un

espacio de

integración

creciente por la construcción de ferrocarriles y el

sistema de

ciudades fronterizas desde San Diego-

Tijuana hasta Laredo-Nuevo Laredo. ra común será una centenaria fuente de problemas, pero no será el único. El contrabando tomó carta de naturaleza y para muchas ciudades fronterizas se convirtió en su razón de ser. Otros asuntos transfronterizos plantearon desencuentros y mutuos reproches en siglos precedentes como los esclavos fugitivos y los ladrones de ganado. Algunos han desaparecido, pero otros (como el contrabando y la custodia de la frontera, la zona libre y la bioseguridad) siguen allí. Entender los viejos problemas nos ayuda a captar mejor cómo y por qué adquiere relevancia el tema de la migración indocumentada y -ya muy avanzado el siglo xx-el desafío de los traficantes de drogas.

La frontera es una fuente de conflictos, pero también es un espacio de integración creciente por la construcción de ferrocarriles y el sistema de ciudades fronterizas desde San Diego-Tijuana hasta Laredo-Nuevo Laredo. Los capítulos dedicados a los primeros pasos de la integración económica y los debates comerciales tienen virtud de ubicarnos en la muy compleja relación triangular entre México, Estados Unidos y Gran Bretaña, además de ubicarnos en los debates internos del proteccionismo estadunidense.

Algunos aspectos menos conocidos de la relación bilateral se reseñan en esta obra para provecho del lector. Por ejemplo, cuando Estados Unidos entró a la primera guerra mundial en 1917, se inició el movimiento de los llamados slackers que se refugiaron en México para evitar ser enrolados. Tiene también un enorme mérito el tratamiento de las relaciones durante el periodo revolucionario. Los intercambios ideológicos y científicos empezaron a adquirir cierta relevancia conforme avanzaba el siglo xx y, aunque usualmente el eje de reconstrucción de la relación ha sido el político, en esta obra no se pierden de vista las dimensiones económica, cultural y mediática.

También resulta interesante ver cómo se conforman ciertos patrones de comportamiento a partir de la ubicación de regularidades y discontinuidades. Por ejemplo, en el tema de seguridad, tan comentado en estos tiempos, observamos que México ha tenido, en el largo espacio de un siglo, tres momentos para coincidir con su vecino en la lucha contra un enemigo externo. Lucha contra enemigos externos, en principio, que ayudó a crear mayor cercanía espiritual que facilitó la institucionalización de las relaciones y la creación de mayor confianza entre los aliados. Aunque con diferencias en el tratamiento de éstas, es posible identificar 
tres ocasiones en que se abordaron con un patrón de comportamiento similar: cooperación, sí, pero con una respuesta lenta y confusa.

No es cuestión de justificar ni de criticar lo que en cada uno de los momentos los sucesivos gobiernos mexicanos pudieron o quisieron hacer. El primero ocurre en la primera guerra mundial, cuando Alemania inicia un acercamiento al régimen de Carranza. El gobierno tiene entonces una respuesta ambigua y lenta a las autoridades estadunidenses para asegurar que México no tiene intención de cooperar con sus enemigos ultramarinos. Durante la segunda guerra mundial, la relación es más complicada y la posición de México, más relevante. De esa etapa provienen las interacciones institucionales más serias en materia laboral (el Programa Bracero), en el ámbito comercial (un tratado que México terminará denunciando) y en cuestión de seguridad, la aportación mexicana concluyó con la participación del Escuadrón 201 en la segunda guerra mundial y la participación de varios miles de conscriptos mexicanos en el ejército de Estados Unidos. De cualquier manera, México no se afianzó entonces como un aliado sólido de aquél por sus explicables reticencias respecto al vecino del Norte. Nuevamente, la respuesta mexicana fue cooperar con él para enfrentar al enemigo externo, pero al igual que en años antes, la respuesta fue tortuosa y confusa. Una situación muy similar ocurrió en 2001, cuando el gobierno de Fox no acertó a articular una respuesta clara y contundente capaz de acercar las preocupaciones comunes en términos de seguridad. Una vez más, México cooperará con su vecino para enfrentar la amenaza externa, pero eso no se traducirá en mayor confianza ni en una mayor institucionalización de la relación en esta materia.

José Luis Ortiz Garza (2007) ha estudiado el clima de opinión (no muy favorable a los aliados) en los medios mexicanos de aquella época. Muy interesante resulta el trabajo del Consejo Coordinador de las Relaciones Comerciales y Culturales Interamericanas, conocido después por sus siglas OIAA, presidido por Nelson Rockefeller. El proceso de americanización de México se describe detalladamente y se explica buena parte de lo que vendría a finales del siglo xx en cuestión de integración comercial. El proyecto político y económico de la revolución mexicana intentó industrializar el país y reducir la dependencia de Estados Unidos, pero la enorme fuerza de las corporaciones estadunidenses y su portentosa capacidad de innovación ganaron la partida.

Los últimos capítulos del segundo volumen presentan de manera concisa y solvente la evolución de la "relación especial", así como el inicio
Durante la segunda guerra mundial, la relación es más complicada y la posición de México, más relevante.

De esa etapa provienen las interacciones institucionales más serias en materia laboral (el Programa Bracero), en el ámbito comercial [...] y en cuestión de seguridad [...]. 
La enorme complejidad

del tema agrario es tratado en todos los capítulos de una u otra manera, para terminar ilustrando con una visión caricaturalmente dicotómica el antes y después del tLCAN para el campo mexicano. de la crisis del modelo de desarrollo autosustentado que México desplegó desde mediados del siglo xx. Lo que me parece argumentalmente disfuncional es la explicación de la situación del campo mexicano por efecto del TLCAN. La enorme complejidad del tema agrario es tratado en todos los capítulos de una u otra manera, para terminar ilustrando con una visión caricaturalmente dicotómica (Riguzzi y de los Ríos, eds., 2012: 533) el antes y después del TLCAN para el campo mexicano.

En efecto, en esa página se incluye una caricatura de un árbol frondoso antes del TLCAN y un árbol seco y con cuerdas que presagian ahorcados después del TLCAN. Quizá sea, así lo entiendo, una muestra del clima de opinión no compartido por los autores, pero, por ocurrente que sea Barajas, autor de la ilustración, resulta contradictoria con la argumentación desplegada previamente.

Por otra parte, se señala: “a partir de 1966, la producción de alimentos es menor al crecimiento de la población y México se convierte en un importador de cereales, sobre todo de Estados Unidos" (390), más adelante los autores acotan: "la agricultura mexicana se bifurca entre un sector atrasado y uno moderno de exportación. La producción de alimentos en los terrenos de temporal se estanca y la producción de granos para consumo humano se reorienta hacia la alimentación animal [...]" (Riguzzi y de los Ríos, eds., 2012: 421). En consecuencia, no parece, preciso culpar al TLCAN de la precaria situación del campo mexicano. Es más, si se observa la trayectoria de las exportaciones agrícolas de México a Estados Unidos, se constata una trayectoria ascendente desde 1993 a 2006 (Riguzzi y de los Ríos, eds., 2012: 552).

Por otra parte, una obra tan cuidadosa -en términos de "corrección política" - sorprende que llame "sectas" protestantes (Riguzzi y de los Ríos, eds., 2012: 430) a las que se suele denominar como iglesias protestantes. Hay otros errores menores, como el de la página 438 , donde se señala: "por primera vez, después de veinte años de estabilidad cambiaria, en 1976 la moneda pasa en un lapso de unos meses de 25 a 150 pesos por dólar [...]". Cabe recordar que en la devaluación de septiembre de 1976, el tipo de cambio, que había estado fijo desde 1954, fue devaluado un 59 por ciento (Kuntz, 2010: 523): el dólar pasó de 12.50 a 20.50 pesos (Banco de México, s.f.). A los 150 pesos llegaría hasta los años ochenta.

Estos detalles no son óbice para considerar que la publicación de esta colosal obra denota el liderazgo académico de los autores y es una gran noticia para todos aquellos que, de una u otra manera, formamos parte 
de la comunidad interesada en la relación bilateral. Pero no solamente para ellos, lo es también para el público en general. Es una obra, gigantesca es cierto, pero muy aleccionadora además de accesible y agradable.

\section{BibLiografía}

\section{Analizada}

Terrazas y Basante, Marcela, Gerardo Gurza Lavalle, eds.

Riguzzi, Paolo y Patricia de los Ríos, eds.

2013 Las relaciones México-Estados Unidos, 1756-2010, vol. I: Imperios, repúblicas y pueblos en pugna por el territorio, 1756-1867/vol. II: ¿Destino manifiesto?, 1867-2010, México, IIH-CISAN, UnAM/SRE.

\section{Consultada}

BANCO DE MÉXICO

s.f. México, Banco de México (Serie Histórica).

JOHNSON, PAUL

2004 Estados Unidos: la historia, Buenos Aires, Javier Vergara.

KUnTZ FICKER, SANDRA

2010 Historia económica general de México. De la Colonia a nuestros días, México, El Colegio de México/Secretaría de Economía.

OrTiz GARZA, José Luis

2007 Ideas en tormenta. La opinión pública en México en la segunda guerra mundial, México, RUz.

Prescott, William H.

2004 Historia de la conquista de México, Madrid, Antonio Machado Libros.

Terrazas y Basante, Marcela

2005 Dos siglos de relaciones México-Estados Unidos. Guía bibliohemerográfica 1974-2005, México, IIH-UNAM. 
VÁZQuez, JOSEFInA Zoraida y LORENZO MEYER

2003 México frente a Estados Unidos. Un ensayo histórico 1776-2000, cuarta edición, México, Fondo de Cultura Económica. 